\title{
Root resection in maxillary molar with a retained fractured instrument and periodontal defect
}

\author{
Naziya Butt ${ }^{1} \&$ Sangeeta Talwar ${ }^{2}$
}

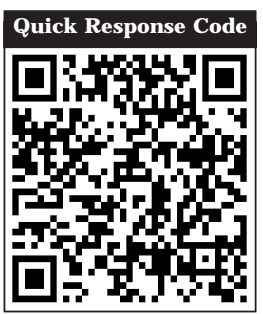

doi: 10.5866/2014.621546

${ }^{1 \& 2}$ Department of Conservative Dentistry \& Endodontics

Maulana Azad Institute of Dental Sciences MAMC Complex, Bahadur Shah Zafar Marg. New Delhi-110 002

India

\section{Article Info:}

Received: J anuary 9, 2014

Review Completed: February 10, 2014

Accepted: March 11, 2014

Available Online: J uly, 2014 (www.nacd.in)

(c) NAD, 2014 - All rights reserved

\section{Email for correspondence:}

dr.naziyabutt@gmail.com

\begin{abstract}
:
To present a successful endodontic-periodontal case involving management of a retained instrument fragment in maxillary molar accomplished with the help of mesiobuccal root resection. Endodontic surgery cannot replace nonsurgical root canal retreatment; however, when indicated, it is a treatment modality that can enhance the outcome. Mesiobuccal root resection surgery was performed concomitant with guided tissue regeneration (GTR) therapy to manage endodontic-periodontal combined lesion in tooth 16. At 12 month follow-up, the tooth showed no mobility, 2-3 mm pocket depths and no further bone Ioss. Root resection combined with GTR therapy can create an optimum environment with a good long-term prognosis.
\end{abstract}

Key words: endodontics, fractured instrument, guided tissue regeneration, root resection.

\section{INTRODUCTION}

Root resection procedures have long been used as a treatment modal ity in various clinical situations involving multirooted teeth. ${ }^{1}$ This procedure may be indicated for several endodontic and periodontal reasons, including severe bone loss around one root, extensive subgingival caries affecting one root only, dehiscence with an entire root exposed, root perforation due to resorption or instrumentation, inability to root fill a canal due to blockage, or extreme curvature and root fracture. ${ }^{2}$ When apical pathosis persists and no apparent benefit can be gained by an orthograde approach, or the risk to the tooth is great (e.g. fracture, procedural errors, separated instrument, or calcified canals), apical surgery should be considered. ${ }^{3}$

The prognosis of root resection has been welldocumented. Some investigators reported that rootresected molars had $>90 \%$ survival rate, whereas other investigators reported that $30 \%$ of resected molars failed over a 10 -year period. ${ }^{4-6}$ The presence of an instrument fragment alone within the root canal is not enough to determine the treatment outcome, but canal infection associated with a 
retained instrument fragment might lead to a poor prognosis. ${ }^{7}$ When infection is present and removal or bypassing of the fractured instrument is difficult due to anatomical complexities, root-resection of a multirooted tooth may ensure more predictable outcomes.

This article presents a successful case of endodontic-periodontal combined lesion with a retained instrument fragment in maxillary molar managed with mesiobuccal root resection and guided tissue regeneration (GTR).

\section{Case Report}

A 21-year-old lady reported to the department of conservative dentistry and endodontics at Maulana Azad Institute of Dental Science with throbbing pain related to tooth 16 . The patient's medical history was non-contributory. Tooth 16 exhibited severe sensitivity and pain to palpation and percussion but no swelling and suppuration.

Clinically, tooth 16 had a coronal temporary restoration, and the previous root canal treatment attempt had been performed 6 months earlier. The direct buccal probing depth was $3 \mathrm{~mm}$ into the buccal furcation area with grade I mobility. A periapical radiographic view revealed a separated instrument fragment in apical third of the MB root extruding beyond the radiographic termination of the root apex with associated periapical radiolucency around the MB root apex (Figure 1a). I nitial diagnosis of tooth 16 was symptomatic apical periodontitis. The tooth also had buccal class I furcation involvement with horizontal bone loss. Therefore, the overall classification was given as an endodonticperiodontal combined lesion. The prognosis was determined as fair. The treatment options were as follows: (i) retreatment, (ii) MB root resection or (iii) extraction and implant placement. The patient wanted to save the tooth. The MB root resection was chosen over the retreatment option as tooth 16 had Class I buccal furcation involvement and the MB root showed fractured instrument apical to the root curvature with thin dentinal wall coronally.

The patient was administered local anaesthesia of $2 \%$ lidocaine with 1:100000 epinephrine (Xylocaine; AstraZeneca Pharma Ind Ltd, Bangalore, India). Under rubber dam isolation, the coronal restoration and all root canal filling materials were removed and the access cavity was modified. Working lengths for the palatal and DB canals were determined with an apex locator (Root ZX; Morita, Tokyo, Japan) and confirmed radiographically. Coronal flaring for all root canal orifices was performed with Gates Glidden drills. The root canals were prepared in a crown-down method using ProTaper $\mathrm{Ni}-\mathrm{Ti}$ rotary instrumentation (Dentsply Maillefer) under copious irrigation with $2.5 \%$ sodium hypochlorite and $17 \%$ EDTA (Prime Dental Product Pvt Ltd, Mumbai, India). The canals were dried with absorbent points (Dentsply Tulsa, Tulsa, OK, USA), and an intracanal dressing with calcium hydroxide paste (Calcicur; VOCO, Cuxhaven, Germany) was placed.

The patient was recalled after a week at which time the tooth was asymptomatic. The calcium hydroxide was removed and a final irrigation was performed with $2 \%$ chlorhexidine. The canals were dried with absorbent points (Dentsply Tulsa) and filled using Protaper gutta-percha points (Dentsply Maillefer) and AH-Plus sealer (Dentsply Tulsa). The tooth was then restored temporarily with Cavit (3M ESPE AG, Seefeld, Germany). A postoperative radiograph (Figure $1 b$ ) was taken, and the patient was asymptomatic during the follow-up period.

After 2 weeks, MB root resection was performed concomitant with GTR therapy (Figure 1c). Under local infiltration anaesthesia, a buccal full-thickness triangular flap was elevated from tooth 15 to tooth 17. After the MB root was resected (Figure $1 d$ ), glass ionomer restoration (F uji I X, GC, Europe), was used to seal the pulp chamber at the furcation area. The remaining roots were planed. One capsule of 250 mg tetracycline $\mathrm{HCl}$ diluted with saline was applied repeatedly to the remaining root surface using cotton pellets.

Sybograf'M plus (Eucare P Ltd, Chennai, I ndia) was gently packed into the defect (Figure 1e). The flap was repositioned and secured with 3-0 monofilament suture. A postoperative radiograph was taken (Figure 1f). A 7-day course of amoxicillin $500 \mathrm{mg}, 3$ times a day, and Peridex ${ }^{\mathrm{TM}}$ (3M, St. Paul, MN, USA) were prescribed. The suture was removed 10 days later. A new core restoration with a posterior composite resin (Filtek Z350; 3M Dental Products, St Paul, MN, USA) was built up. After 6 months, a new crown was fitted (Figure 2a). Tooth 16 was not mobile and 2-3 mm probing depths. At 12 months follow-up, the tooth was asymptomatic to percussion and palpation. Periodontal probing was within normal limits, complete healing and no further bone loss were observed on the radiographs (Figure $2 b$ ). 

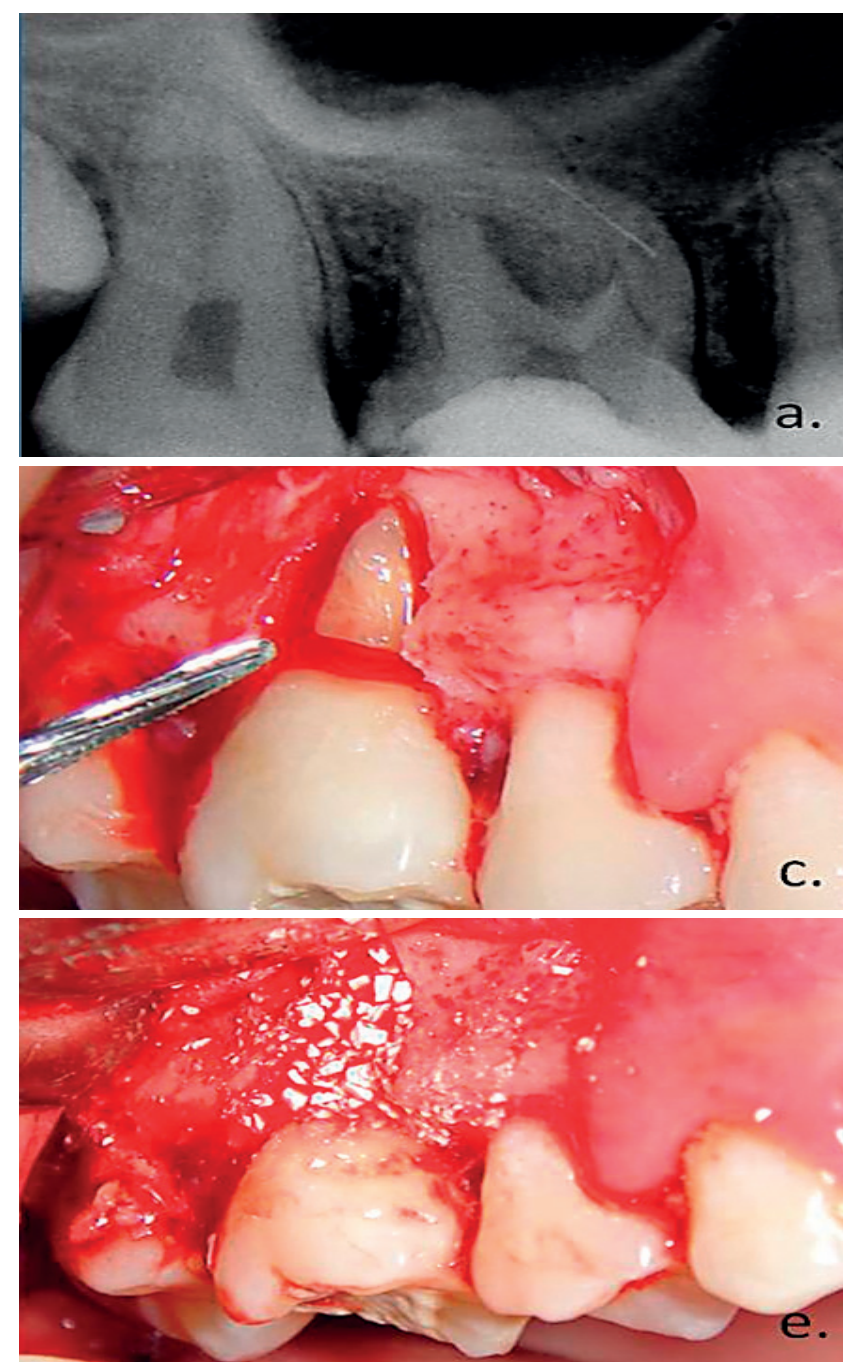
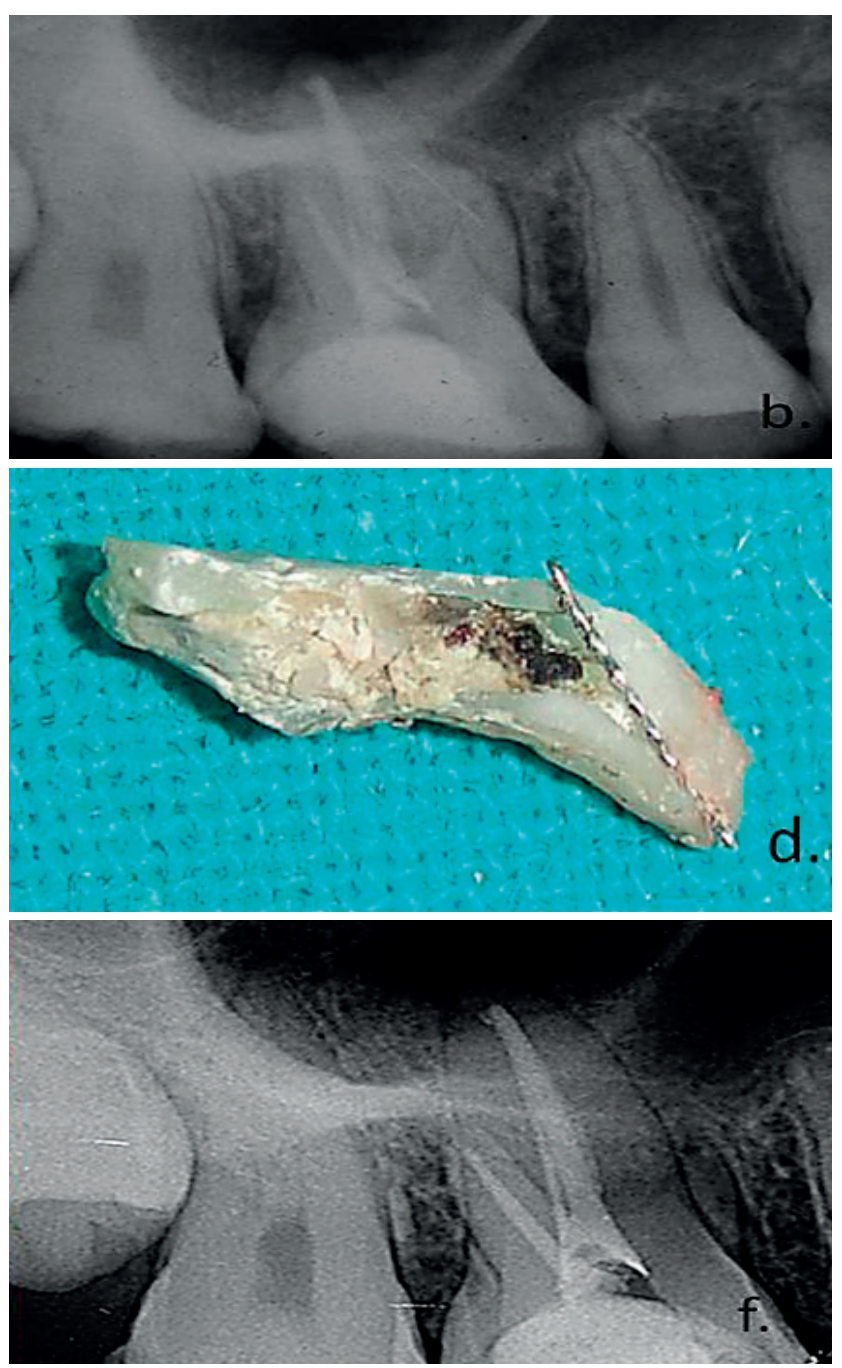

Figure 1: (a) I nitial radiograph showing a separated instrument fragment and periapical radiolucency around the mesiobuccal root of tooth 16. (b) Post obturation radiograph of tooth 16. (c) A full thickness mucoperiosteal flap reflected and MB root resected. (d) Resected root with separated instrument. (e) Defect packed with the bone graft material. (f) Radiograph after the mesiobuccal root resection and guided tissue regeneration procedure.
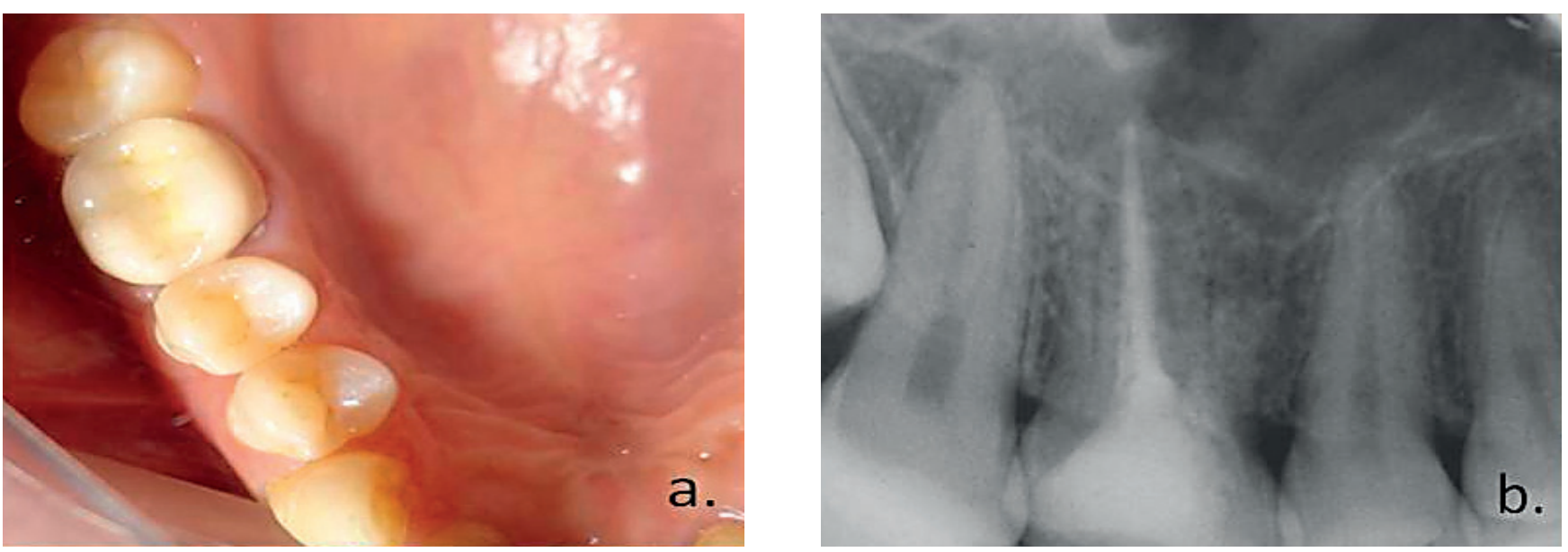

Figure 2: (a) Metal ceramic crown fabricated for tooth 16. (b) 12-month follow-up radiograph 


\section{DISCUSSION}

Root-resection therapy is a treatment option for molars with periodontal, endodontic, restorative, or prosthetic problems. The present report demonstrates the management of endodonticperiodontal combined lesions with root resection and GTR application. Root resection could be considered when there is no periapical resolution after root canal treatment as this procedure often eliminates the infection source. ${ }^{8}$ Tooth 16 had symptomatic apical periodontitis with a retained instrument fragment in the apical third of MB root. Ruddle stresses that ultrasonic tips should only be used for fractured instrument removal when the separated fragment is visible under the DOM. ${ }^{9}$ Unnecessarily vigorous use of ultrasound as well as use of ultrasonic tips in more apical regions of the root canal could lead to adverse outcomes such as root perforation or weakening. ${ }^{10}$ Since the fractured instrument could not be visualized with the aid of a DOM, resection the MB root was chosen in the present case.

The prognosis of endodontic-periodontal combined lesions is considered poor as their treatments are challenging and require both endodontic and periodontal tissue healing. ${ }^{8}$ Surgical endodontics is undertaken in cases where retreatment is inappropriate to treat persisting or emerging disease following root canal treatment. The objectives of guided tissue regeneration in endodontic surgery is to facilitate tissue regeneration by creating an optimum environment. ${ }^{11}$ When root resection with GTR is carried out in maxillary molars, it results in a unique environment dictated by the contours of the remaining roots and the residual furcation between them. Furthermore, Klavan demonstrated that the removal of one root of a maxillary molar did not increase the mobility of a tooth in normal function. ${ }^{12}$

A metal ceramic crown was fabricated for tooth 16 where the MB cusp was reduced but not eliminated to provide convex crown morphology. A maxillary molar has a large enough surface area to provide retention for an overlying casting. In such cases, the occlusion should be carefully evaluated, and the teeth crowned to prevent a vertical root fracture, which is one of the most common complications observed following root resection procedures. ${ }^{13}$

\section{CONCLUSION}

The present case report demonstrated that rootresective therapy with GTR technique can be considered an effective measure to resolve endodontic and periodontal problems of furcation defects in molars and to maintain a favorable longterm prognosis of the treated teeth. Periodontal problems around resected molars have a tendency to recur and should be maintained through meticulous supportive periodontal treatment. In addition, a careful prosthetic plan should be designed to avoid a fracture of resected molars related to biomechanic impairment.

\section{REFERENCES}

1. Green EN. Hemisection and root amputation. J Am Dent Assoc 1986; 112: 511-518.

2. J ohnston DJ , Cowan CG, Hussey DL. An Unusual Indication for Root Resection. J Endod 2000; 26:248-250.

3. Degerness R, Bowles W. Anatomic Determination of the Mesiobuccal Root Resection Level in Maxillary Molars. J Endod 2008; 34:1182-1186.

4. Carnevale G, Di Febo G, Tonelli MP, Marin C, Fuzzi M. A retrospective analysis of the periodontal-prosthetic treatment of molars with interradicular lesions. Int J Periodontics Restorative Dent 1991; 11:189-205.

5. Carnevale G, Pontoriero R, di Febo G. Long-term effects of root-resective therapy in furcation-involved molars. A 10year Iongitudinal study. J Clin Periodontol 1998; 25:2092014.

6. Langer B, Stein SD, Wagenberg B. An evaluation of root resections. A ten-year study. J Periodontol 1981; 52:719722.

7. Panitvisai P, Parunnit $\mathrm{P}$, Sathorn C, Messer HH. Impact of a retained instrument on treatment outcome: a systematic review and meta-analysis. J Endod 2010; 36:775-780.

8. Oh SL, Fouad AF, Park SH. Treatment strategy for guided tissue regeneration in combined endodontic-periodontal lesions: case report and review. J Endod 2009; 35:13311336.

9. RuddleCJ . Nonsurgical retreatment. J Endod 2004; 30:827845.

10. Suter B, Lussi A, Sequeira P. Probability of removing fractured instruments from root canals. Int Endod J 2005; 38:112-123.

11. Dietrich $T$, Zunker P, Dietrich D, Bernimoulin J P. Periapical and periodontal healing after osseous grafting and guided tissue regeneration treatment of apicomarginal defects in periradicular surgery: results after 12 months. Oral Surg Oral Med Oral Pathol Oral Radiol Endod 2003; 95:474-482.

12. Klavan B. Clinical observations following root amputation in maxillary molar teeth. J Periodontol 1975; 46:1-5.

13. Needleman I. How long do multirooted teeth with furcation involvement survive with treatment? Evid Based Dent 2010; 11:38-39. 